\title{
Undertaking access audits and appraisals: An inclusive design approach
}

Received (in revised form): 7th January, 2005

\begin{abstract}
Marcus Ormerod MRICS
is a registered access consultant, chartered surveyor and senior lecturer. He facilitates an MSc programme in Accessibility and Inclusive Design that is studied by distance learning via the internet, and he acts as a consultant on access issues for a wide range of clients. He has undertaken major research projects on inclusive design and access issues and written widely on the subject. As Director of the SURFACE Inclusive Design Research Centre he co-founded the Accessibuilt discussion list that provides a rich knowledge resource for practitioners (http:// www.jiscmail.ac.uk/lists/accessibuilt.html).
\end{abstract}

\begin{abstract}
This paper sets out an inclusive design approach to access audits based on the social model of disability. The difference between access audits and appraisals is examined. The audit process is explored from the client brief through the planning stage, including details of what should be audited. The range of equipment available to an access consultant to collect data while on site is explained. The features of the buildings that are analysed in an access audit are provided and consideration is given to solutions not covered by current guidance.
\end{abstract}

\section{Keywords:}

accessibility, auditing, disability, inclusive design, surveys, Disability Discrimination Act (DDA)

\section{DISABILITY AND INCLUSIVE DESIGN}

The gradual implementation of the Disability Discrimination Act $^{1}$ (DDA) over the past ten years has seen a new specialist discipline emerge within building appraisal, namely the access auditor/consultant. People acting as access consultants can come from wide-ranging backgrounds, such as occupational therapy, architecture, building surveying, disability studies, building control etc. Consultants may or may not have personal experience of disability and this has been put forward as an important criteria in understanding the issues related to accessibility. ${ }^{2}$ It is arguable that, although an understanding of disability is important in access auditing, it is unlikely that a single person, or even a small group of people, would have a comprehensive base covering a wide range of

Marcus Ormerod NRAC Access Consultant SURFACE Inclusive Design Research Centre, The University of Salford Bridgewater Building Salford, M7 1NU, UK

Tel: +44 (o)7887 56425 E-mail: m.ormerod@salford.ac.uk impairments (pan-disability); while ideally a large group of people conducting an audit would uncover many different issues, it would not be feasible for many clients.

The basis on which the audit is approached is important and the client's brief is crucial in establishing the criteria that form the baseline of the audit. It is not sufficient just to state in the brief 'the audit should provide 
Parts of the DDA

\section{Definition of inclusive design}

DDA compliance'. The DDA is divided into various sections with definitions of disability in Part 1; employment issues in Part 2; goods, facilities and services in Part 3; education in Part 4; and public transport in Part 5. Depending on the nature of the client's business there may be DDA requirements in multiple parts of the Act and the relevant parts to be considered should be stated in the brief. For example, an academic institution would need to consider Parts 2, 3 and 4. It should be noted also that there can be no guarantees of 'compliance' with the DDA through undertaking an access audit. While an audit may lead to the development of an access strategy (Flanagan et al., 2004) to improve the built environment, it cannot itself provide 'compliance' since the nature of the Act is dependent on judgments about what is reasonable in individual cases. The client's brief should also state the level of standards that the building should be measured against, such as relevant building regulations and approved documents (Part $\mathrm{M}^{3}$ and Approved Document $\mathrm{M}$ in England and Wales, Part $\mathrm{M}^{4}$ in Northern Ireland, or Technical Standards ${ }^{5}$ in Scotland), BS8300 ${ }^{6}$ or other better practice guidance such as Inclusive Mobility ${ }^{7}$ or Accesscode. ${ }^{8}$ Hopefully, the client will want to go further than minimum standards and towards best practice. A more holistic approach is to take an inclusive design perspective.

Inclusive design is a way of designing products and environments so that they are usable and appealing to everyone, regardless of their age, ability or circumstances, and works with users to remove barriers in the social, technical, political and economic processes underpinning building and design (Ormerod et al., 2002). Although this is more effective if it is applied at the outset of a new-build, the philosophy can be applied to existing buildings. The inclusive design approach is based on the social model where a clear distinction is made between an individual's impairment and the disabling barriers that society creates.

\section{SOCIAL MODEL OF DISABILITY}

Society is created and operates in a way that does not take into account those people who do not meet its perceived norm, society excludes such people and thereby disables them. This interpretation of disability is termed the social model of disability. In this definition, 'impairment' relates to an individual's condition of mind, body or senses that results in an individual functional limitation; 'disability' refers to the limitations imposed by a society that takes no account of people with impairments. Consequently, people with impairments are 'disabled' by society. By this definition, the term 'people with disabilities' makes no sense.

Using the social model of disability allows one to consider how disabling barriers are, such barriers may be not just physical but also attitudinal, systematic and institutionalised. Knowing that the barriers are socially created and operated means that they can be tackled at source rather than ignoring them as incidental in the belief that the problem is with the individuals who are excluded. These barriers are present in areas as diverse as education, employment, leisure, transport, urban design and housing. One individual can encounter disabling barriers several times a day in all these spheres, making disability a whole life experience. 


\section{Access appraisal}

\section{Access audit}

\section{Checklists}

The social model of disability allows recognition that the causes of disabling barriers in design are influenced by the broader social and cultural context. This enhances insight into the ways in which disabled people are excluded by the built environment and poorly designed artefacts. In order to make best use of the social model of disability it is important to be clear about which limitations are caused by an individual's impairment (difference in mind, senses or body) and which barriers are created by society.

\section{AUDIT OR APPRAISAL?}

There is a distinction between an access audit and an access appraisal. Access audits are undertaken for existing buildings or environments to examine the current situation and should make recommendations for improvements. Access appraisals are carried out as part of the design process of new buildings or environments. It is usual with appraisals to be asked to make comments at key stages in the development of the design as more detail becomes apparent. This paper focuses on access audits.

Access audits, according to Holmes-Siedle (1996), fall into two categories:

- Those that assess the presence of facilities for disabled people.

- Those that are designed to assess how well the facilities in the building will work for disabled people.

The main difference between the two types of audit relates to the way in which they are carried out. The first type relies mainly on a tick-box exercise to identify the presence or lack of a facility. The second type of audit involves a far more in-depth study of how the building actually works for disabled people, which will give the client the present picture of their building combined with recommendations as to what should be done to improve it.

To illustrate this point, take the example of a toilet. Using the tick-box audit the existence of an accessible toilet would be recorded if evidence existed of its presence, eg a sign on the door, and possibly what was missing from inside the toilet would be noted against the criteria set down on the checklist. The second type of audit differs from the first by investigating the ability of the facility to be used by disabled people. The second, more in-depth, type of survey should identify the problems that inhibit its use and offer recommendations for improvement.

While checklists are often used initially by new access consultants they soon become aides-mémoire rather than being rigidly completed. Many of the computerised systems for auditing rely on checklists that can be completed using handheld devices and then downloaded when back at the office to produce an access audit report in a standardised format. A comprehensive checklist, either on paper or computerised, does allow teams of auditors a common platform and manner in which to conduct audits of large estates, but for individual buildings a trained access consultant is more likely to make the second type of audit and spend more time thinking laterally about solutions to the access issues. 


\section{THE AUDIT PROCESS}

When seeking to carry out an access audit it is essential that the consultant undertaking the audit initially identifies access requirements by

considering and asking questions such as:

\section{Questions to ask}

\section{Quantitative data}

\author{
Qualitative data
}

- Does the client own or rent the premises?

- Where are the boundaries for the audit to be set?

- Who uses the building to be audited?

- How is the building used?

- Does the use of the building change during the course of the day or the seasons?

- Are the needs for staff and visitors the same?

- Is the access requirement long or short term (are the measures being introduced to satisfy the needs of temporary workers or is the organisation intending to stay in the premises for several years)?

- What is the future plan for the premises, are any refurbishments planned?

Once the requirements have been identified, the consultant should then look for the features of the building that could affect accessibility. The audit generally takes the form of a journey through the building (Sawyer et al., 2004) from the point of arrival, through all parts of the building, to enable an assessment of the accessibility of its facilities, management practices, policies and procedures.

When undertaking an audit, some aspects can be measured against the standards on which the audit is to be based (quantitative data), while others can be observed giving a subjective assessment (qualitative data). Checklists tend to concentrate on the quantitative data, but the qualitative information, although harder to measure, is equally as important. Quantitative data include door widths, position of vision panels and manifestations, ramp gradients, corridor widths, height of facilities (toilets, basins, counters etc), circulation space, light levels, noise levels, door-closing resistance and water temperature. Qualitative data include how the building is used, how it is managed, the colour/tonal contrast of surfaces, use of glass and reflections, appropriateness of signage, route finding through the building, quality of acoustics and overall ambience.

\section{Planning an audit}

Prior to visiting the building to be audited it is useful to acquire a current set of plans if they exist. Use of plans enables familiarisation with the general layout of the building, provides an opportunity to identify where some of the major barriers may be before actually getting on site and helps in annotating notes as the consultant goes around the building. If the site contains several buildings, a set of plans will help with orientation and give a better idea of the relationship between the buildings and the spaces around them. It is also worth checking that all the buildings to be audited are on the same site. An organisation may be located on several different sites spread over a large geographical area. 


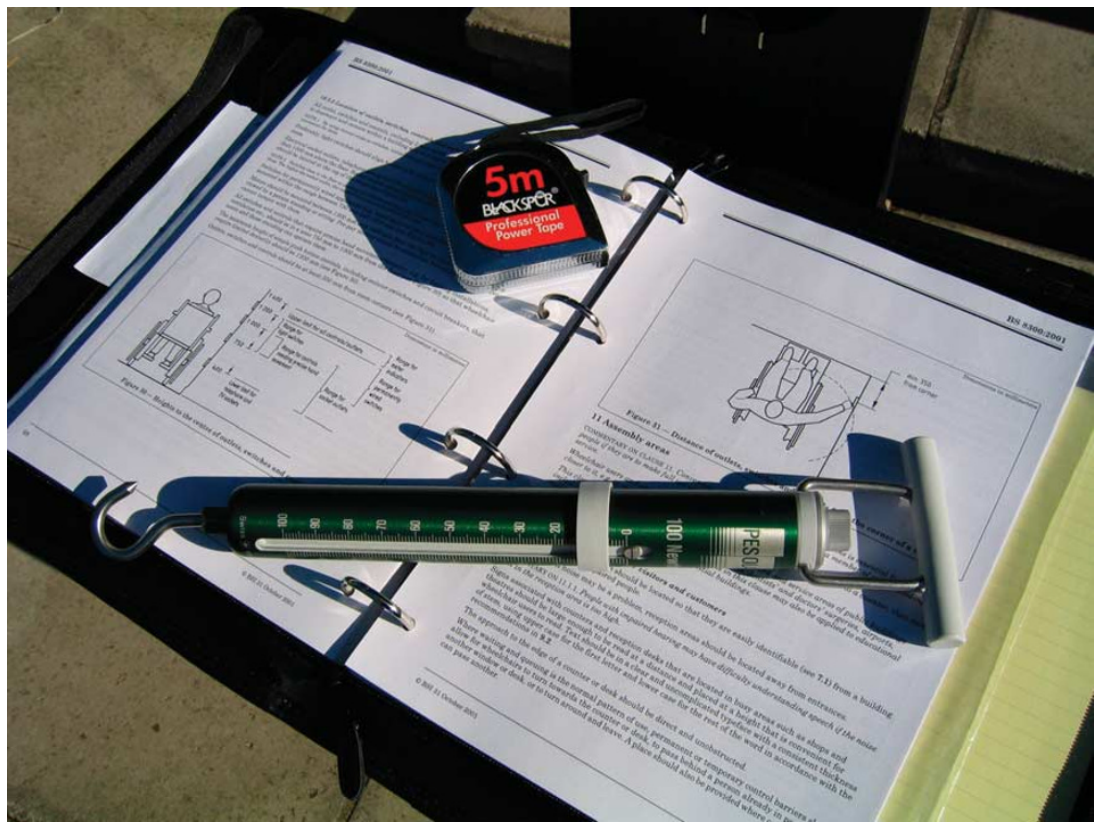

Figure 1: Most-used equipment during the access audit (tape measure and door-closing pressure gauge)

Buildings are used differently at different times of the day and seasons of the year. A visit to a school during the summer will be entirely different from one made during term time. To get a true picture of how the building is used it is best to ensure being on site at different times of the day to understand how people use the building, but this can be restricted by the

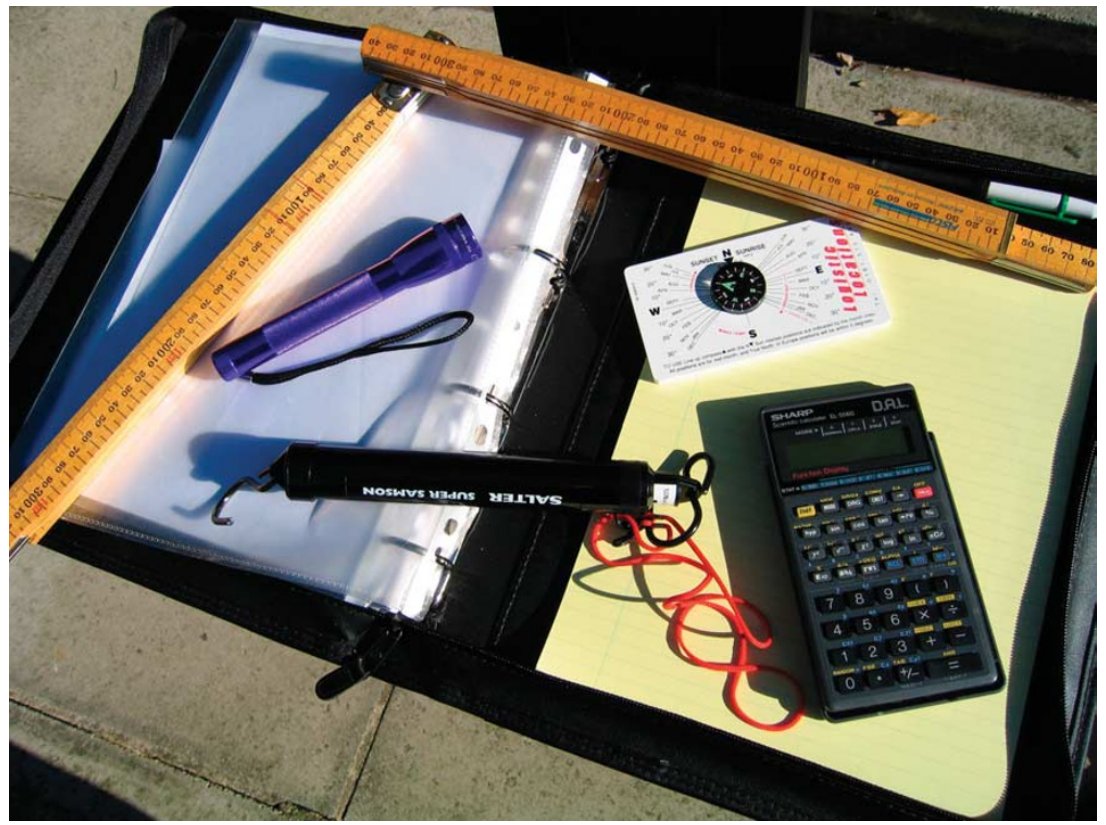

Figure 2: Additional equipment for use during the access audit (ruler, torch, compass, calculator and spring balance) 


\section{Management of the building}

\section{Toolkit}

amount of on-site time allowed by the financial constraints of the commission. It is important that the time spent on site is when people are actively using the building.

\section{What is audited?}

In addition to an identification of the barriers created by the physical design features of the building, consideration must also be given to sensory issues and cognitive aspects. The issue of route finding and how users negotiate their way around the building will need to be considered. This aspect of the audit will involve an assessment of features such as signs and their location, colour/tonal contrast, existence of maps or location guides. The provision of communication equipment and methods of communication used will need to be investigated. The management routines for the building will need to be discovered through discussion with both on-site staff and the senior management team. While, on paper, a building management system may appear to be thorough, it is how the staff in the building utilise the system on a day-to-day basis that makes the building work. Finally, access also means egress and the means of escape in an emergency situation should be considered. The routes taken during an emergency may be very different from those used on a day-to-day basis, especially in terms of vertical circulation.

\section{What equipment is useful to take?}

There is no set toolkit for access consultancy, but in the author's experience the following items will prove useful to have to hand. At the initial meeting with the client it is helpful to take a folder that has an overview of the DDA, BS8300, relevant building regulations and Approved Documents or Technical Standards, copies of the current indemnity insurance policy and a priority chart indicating what bands issues identified in the audit will be classified under (eg priority $\mathrm{A}=$ health and safety issue, $\mathrm{B}=$ attend to within next 12 months, $\mathrm{C}=$ adjust when next refurbished).

The most-used equipment during the audit are the digital camera to record good and bad practice and act as an aide-mémoire when compiling the report back at the office, a tape measure and the door-closing pressure gauge.

Pressure gauges, such as the one illustrated in Figure 1 which is a Pesola Scale Macroline 100N with additional pressure set, are available from http://www.alanaecology.com. Less expensive ones, such as the Salter Super Samson spring balance, shown in Figure 2, only measure pulling pressure not closing pressure (BS8300 specifies closing pressure rather than opening pressure). Also, a piece of string is required to wrap around door handles if measuring pulling pressure with the cheaper-style pressure gauge.

A wooden rule can be used to measure items that are out of reach and a torch can be useful. The compass shown in Figure 2 is a Dubios sun position version that shows the relative positions of sunrise and sunset and is used to work out the building orientation for the purposes of glare. A calculator also can be useful in the event of having to use Pythagoras to 


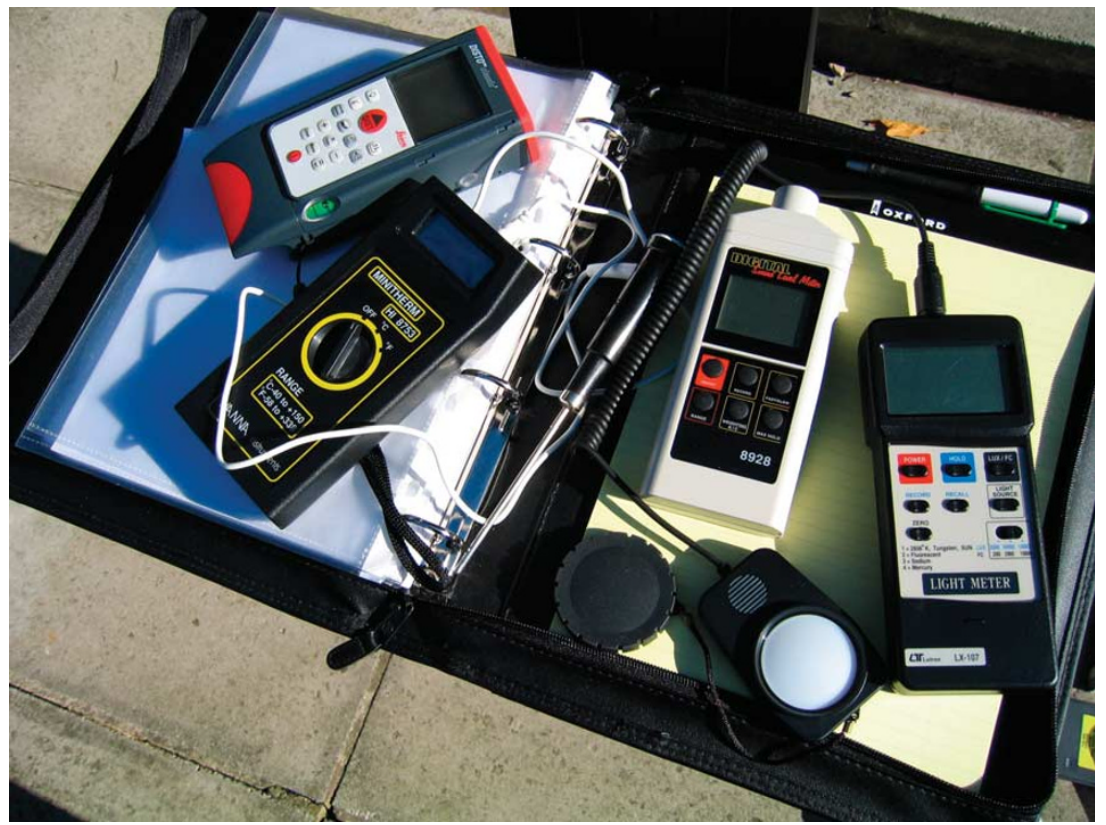

Figure 3: Useful electronic equipment for use during the access audit (for measuring distance, temperature, sound and light)

calculate a gradient. A card with the Braille alphabet and numbering system on it will enable Braille signs to be checked.

Electronic measuring devices, such as the Leica Disto shown in Figure 3, make one-handed measuring easier. A light meter will provide data on light levels for interior rooms and important communication areas. A temperature recording device is useful to measure hot water from taps. A sound meter can give an indication of noise levels, but for accuracy

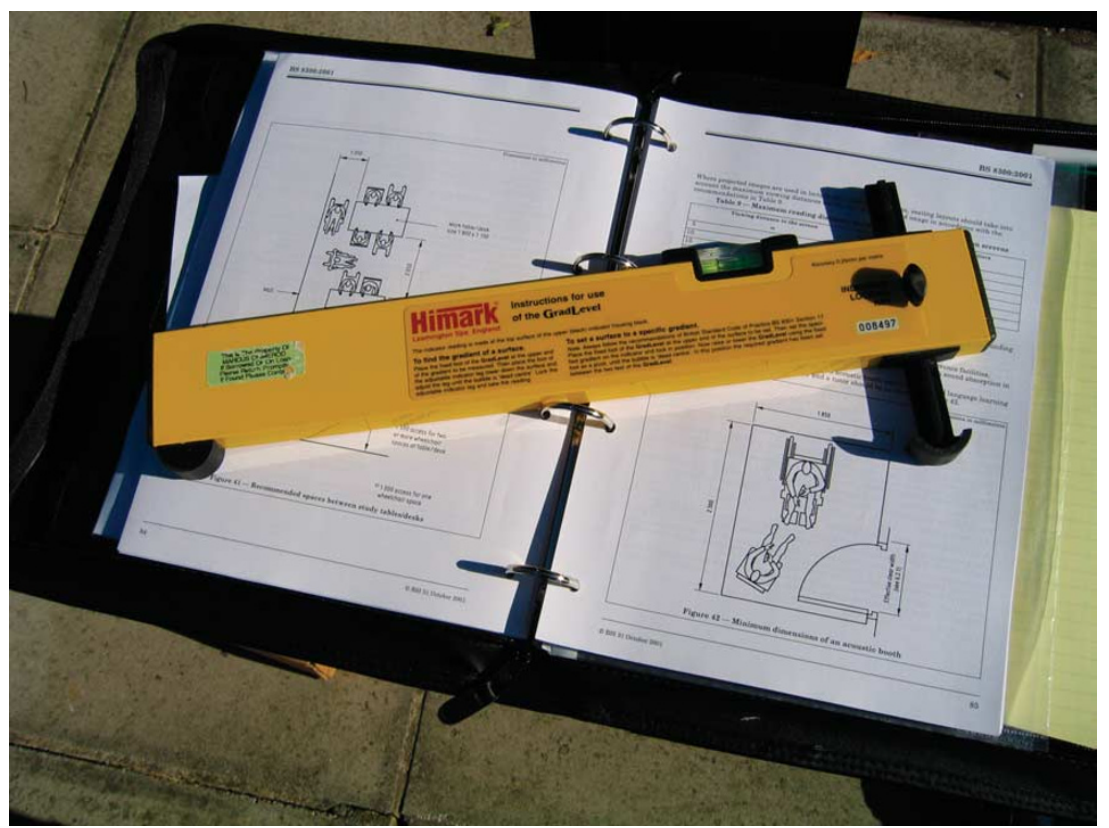

Figure 4: A grad level for measuring ramp gradients 


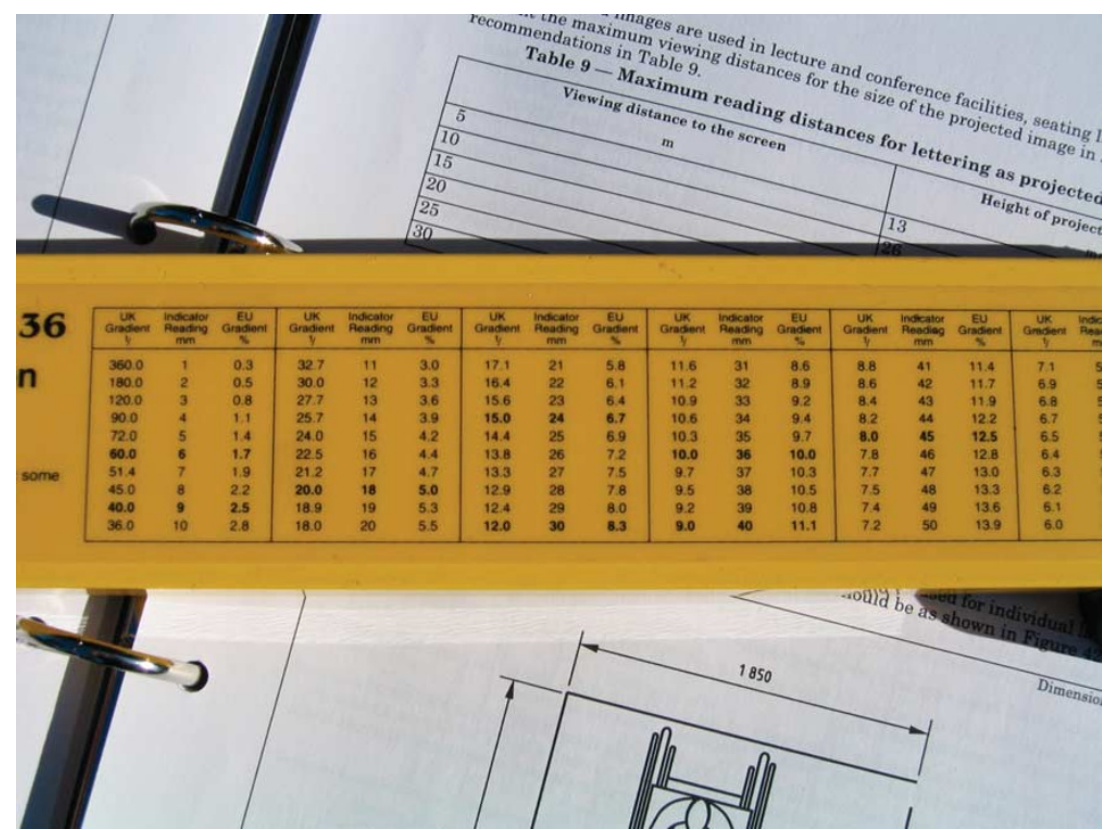

Figure 5: Detail of the conversion a chart used to work out gradients

requires measurements taken over a period of time, generally far longer than that allowable in an access audit.

To measure gradients of ramps a grad level, such as that illustrated in Figure 4, is quick and easy to use (available from http://cae.org.uk). Digital levels, such as the Bosch DNM 60 L or DNM 40 L from http://www.boschpowertools.co.uk/, are also available. But for most

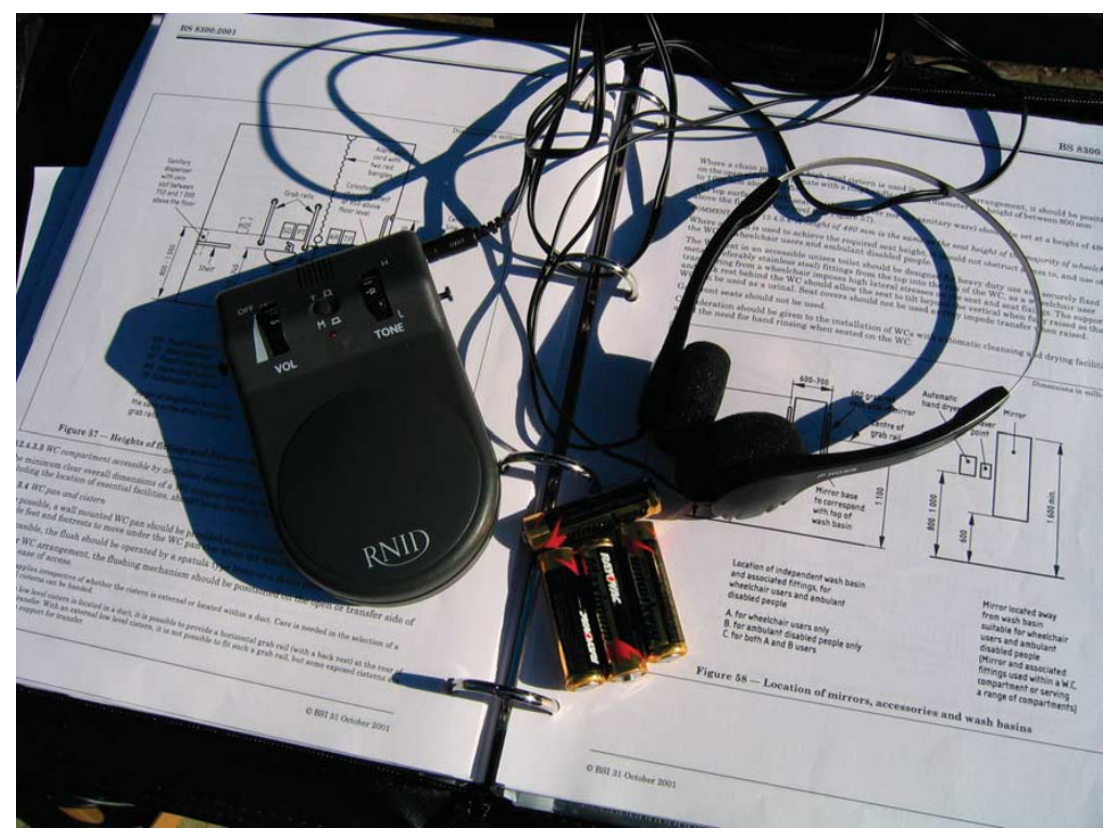

Figure 6: The RNID Crystal Listener with headphones for checking induction loop systems 


\section{Induction loop testing}

Journey approach

\section{Observe people using \\ the facilities}

\section{Key features}

consultants a chart is used to work out what the gradient is in meaningful terms (see Figure 5).

In order to assess if an induction loop is working then a tester is required. A simple version is the RNID Crystal Listener with headphones (available from http://www.rnid.org.uk/index.htm) shown in Figure 6, which allows a hearing user to experience the quality of sound from an induction loop. More sophisticated testers can measure the strength of the signal. These devices are essential for the consultant to be able to test for overspill from the induction loop in areas where sensitive information is being spoken, such as the reception desk at a doctors' surgery (Figure 7).

If taking this amount of equipment around on an audit then the consultant needs something to put it all in. Surveying all day is a tiring experience so finding a toolbox that allows a writing pad to rest on the top makes life more bearable and can form a resting place for the consultant as well. Also, if it has wheels then it will indicate lack of ramps and dropped kerbs.

\section{On-site audit}

It is usually impossible to work around the place to be audited in the logical sequence dictated by the journey approach. Weather conditions mean choosing the most appropriate time to survey the outside. If it is dry the consultant should start outside, but if it turns wet they should proceed inside and return to the outside when it is dry. Cold and damp consultants do not spot nuances in access issues! Areas such as toilets and changing rooms are best tackled early in the day before people start to use them. Getting in when the cleaning staff are working their way around the building increases the number of rooms that will have been opened. Part of the audit is to see how people use the facilities, however, so the consultant should return to the empty rooms when people are about in order to understand how they are really used.

The consultant should observe how the car parking is used and what policing, if any, there is over who gets to park in accessible parking bays. They should watch which entrances people use to come and go in the building. The routes that people who are familiar with the building use and those that strangers take should be identified.

Having lunch in the canteen area while observing people queuing for their food, selecting their seats and circulating around the building gives a better insight than when it is empty. The consultant should look for where people have to go to be able to smoke - a disabled person is just as likely to be a smoker as anyone else. If an area seems to have a barrier but there is no one about then the consultant should make a mental note to return at a later time to see if they are right. Talking to people met en route enables the consultant to get their anecdotal views.

\section{Which features of the building should be analysed?}

- External approaches and environment: The audit should investigate all external approaches to the site and its surrounding environment 
and, ideally, this should include public transport links and car parking. Pedestrian routes to the building from the site access points, parking or drop-off points should be checked to ensure gradients and changes in level are appropriate; there should be no obstructions along the route and the correct tactile paving should be used where appropriate.

- Entrance and reception areas: The location and distance of the main entry point to the building in relation to the route to the building should be examined, along with signage guiding visitors to the main entrance. The visibility of the main entrance door and the mode of operation of the door itself require inspection. The reception desk should be checked to ensure it is designed for a wide range of users (both visitors and staff) and that the area provides an appropriate environment to facilitate communication.

- Horizontal circulation: Internal circulation spaces should be measured to ensure that all doors and corridors, rooms and open plan areas provide sufficient circulation space. Doors along circulation routes should be checked to ensure they are easy to operate and that they are both clearly visible and there is visibility through the doors to see people coming from the opposite direction.

- Vertical circulation: The audit should consider means of vertical circulation and will have to examine both stairs and lifts (if provided) to ensure that both methods are appropriate.

- Toilets: The audit will examine all sanitary facilities - toilets, showers and changing rooms - to ensure that their location within the building, size, location of support rails and other fittings, emergency alarm provision and colour contrast of fittings are adequate.

- Auxiliary aids: The audit will assess whether communication equipment such as telephones, Minicom systems, inductive couplers, induction loops in meeting rooms, visual display systems, reception/till/information areas are provided and if the staff know how to use them. The audit should also consider what is the most appropriate solution for the particular setting in which an auxiliary aid is required.

\section{Wayfinding}

Emergency egress
- Information provision and signs: The audit should assess how easy the building is to navigate around and should comment on route finding, including colour contrast issues, directional signage, use of maps/plans or guides of a building and room signs.

- Lighting: The audit should assess lighting levels to ensure participation and safety of people with visual impairments in critical areas like reception, at work terminals and on steps/stairs.

- Acoustics: The auditor should assess the acoustic properties of the spaces within the building to ensure that unnecessary sound reverberation does not cause problems for people with hearing impairments.

- Emergency exits and fire alarms: The auditor should take into account the emergency fire escape/evacuation procedure and check on visual/audible alarms, refuge areas, emergency signage/lighting, 


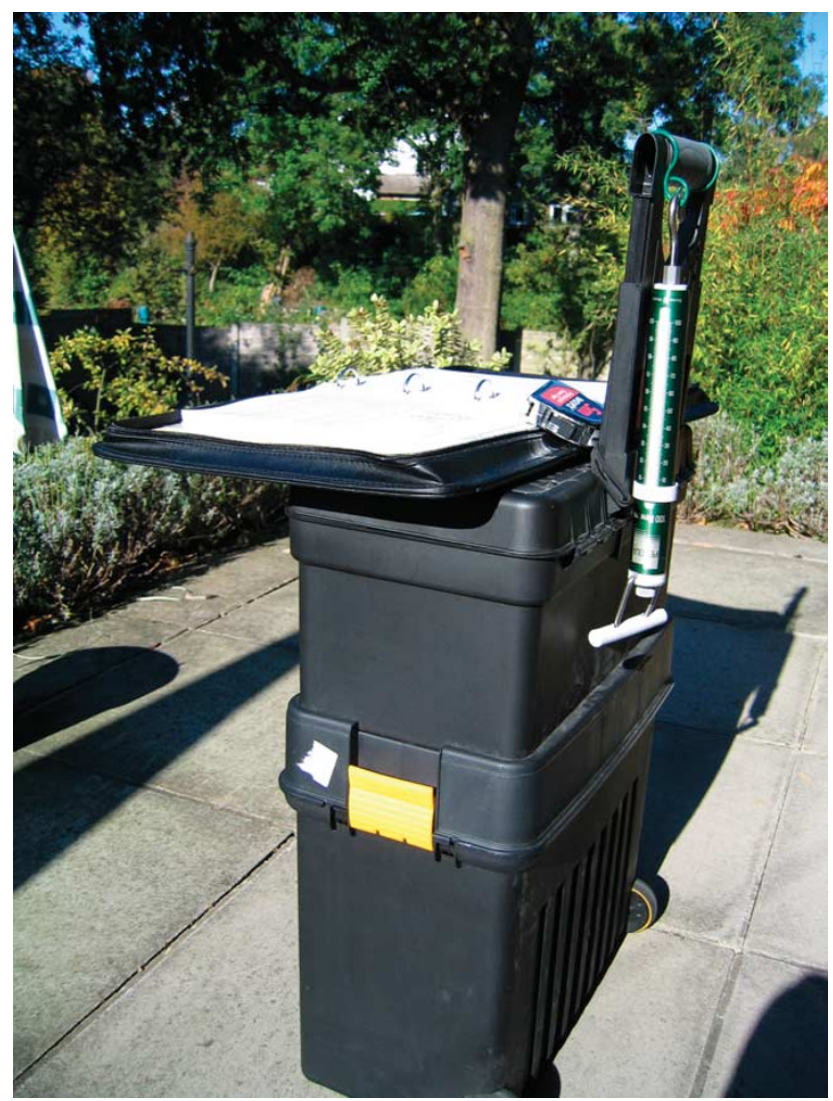

Figure 7: Example of a useful toolbox for carrying the consultant's equipment

\section{Staff attitudes}

location of alarms and extinguishers and provide advice on the development of personal emergency egress plans (PEEPS).

- Policies and procedures: The auditor should consider the policies and procedures that the client has drawn up to ensure the organisation is promoting equality in all aspects of its operations.

- Staff attitudes: Assessing attitudes is important as even an accessible building can be inaccessible to disabled people if staff are unaware/unhelpful. It may be difficult for the auditor to assess attitudes directly during their time on site but it is worth trying to get an idea of how the building staff deal with disabled people. An appropriate way to satisfy this problem might be to ascertain the numbers of staff who have undergone disability equality training, along with an element of observation.

- Information provision: The auditor should assess the information provided by an organisation to ensure that general information provision meets good practice standards. The issues to consider include layout, typographic elements and materials used for the publication, languages used and any images, which must be accessible to all. The assessment should also consider whether the 


\section{Beyond best practice guidance}

client is able to meet a request for information to be provided in an alternative format, ie large print, disk, Braille or tape.

\section{BARRIERS AND SOLUTIONS NOT COVERED BY CURRENT GUIDANCE}

When undertaking an access audit a consultant needs to be constantly looking for potential barriers. Although the majority of these may be solved using best practice solutions, quite often issues arise that are unique and not covered by current guidance. It may be possible to adapt existing guidance to cover a unique situation by using the core principles contained in the guidance. In other situations, primary research will be needed to try to locate possible sources of expertise.

It may be possible to pick up on guidance provided in other countries and adapt this to suit the context and regulations of the particular country that the consultant is working in. There are networks of people interested in access-related fields (such as Accessibuilt), allowing opportunities to explore issues with other people and share solutions.

An illustration of a possible barrier not covered by current guidance is the case of an internal exhibition show that wanted the seating for the show to be placed on a continuously rotating platform. The platform was flush with the stationary element of the exhibition and visitors were required to move on to the moving element before taking their seats. Once the show was finished the visitors then had to get off the moving element to find themselves at the exit point. The access consultant was required to determine the safe speed that the moving platform could revolve at without stopping in order to allow safe transfer of people on and off it. In addition, the consultant had to advise what other provisions the exhibitor needed to give an equal experience to all visitors.

\section{References}

Flanagan, S., Cook, G., Embleton, J., Bright, K. and Selbekk, L. (2004) Buildings for All to Use, CIRIA, London, UK.

Holmes-Siedle, J. (1996) Barrier Free Design, Butterworth-Heinemann Ltd, Oxford, UK.

Ormerod, M.G., Newton, R.N., Morrow, R. and Thomas, P. (2002) 'City unlimited - Inclusive design and the built environment. What is the built environment for, if it is not for people?', fringe event paper at the Office of the Deputy Prime Minister Urban Summit, Birmingham, UK, October.

Sawyer, A. and Bright, K. (2004) The Access Manual, Blackwell, London, UK.

\section{Notes}

(1) The Disability Discrimination Act, details available at: http://www.hmso.gov.uk/acts/ acts 1995/1995050.htm.

(2) Manchester Disabled People's Access Group (2003) Various discussions with access consultant.

(3) Details of Part M and Approved Document $\mathrm{M}$ for England and Wales are available at: http://www.odpm.gov.uk/stellent/groups/odpm_buildreg/documents/downloadable/ odpm_breg_025613.pdf. 
(4) Details of Part M for Ireland are available at: http://www.environ.ie/DOEI/DOEIPol.nsf/0/ b6ca96a0bf2051c180256d3a004c55de/\$FILE/Part\%20M.pdf.

(5) Details of Technical Standards for Scotland are available at: http://www.scotland.gov.uk/ build_regs/standards/contents.asp.

(6) Details of BS8300 are available at: http://www.bsi-global.com/index.xalter.

(7) Details of Inclusive Mobility are available at: http://www.dft.gov.uk/stellent/groups/ dft_mobility/documents/page/dft_mobility_503282.hcsp.

(8) Details of Accesscode available at: http://www.jiscmail.ac.uk/lists/accessibuilt. 